Culture et histoire dans l'espace roman

$12 \mid 2014$

Empreintes/emprunts : entre forces de conformisation et forces d'innovation

\title{
Las Crónicas de Indias en la ópera barroca
}

Discursos y géneros

\section{Ana Núñez Ronchi}

\section{(2) OpenEdition}

Journals

Edición electrónica

URL: https://journals.openedition.org/cher/7495

ISSN: 2803-5992

Editor

Presses universitaires de Strasbourg

Edición impresa

Fecha de publicación: 7 julio 2014

Paginación: 111-127

ISBN: 978-2-86820-569-8

ISSN: 1968-035X

Referencia electrónica

Ana Núñez Ronchi, «Las Crónicas de Indias en la ópera barroca», reCHERches [En línea], 12 | 2014,

Publicado el 13 diciembre 2021, consultado el 15 diciembre 2021. URL: http://

journals.openedition.org/cher/7495

\section{cc) (†) (2)}

Ce(tte) œuvre est mise à disposition selon les termes de la Licence Creative Commons Attribution Pas d'Utilisation Commerciale - Partage dans les Mêmes Conditions 4.0 International. 


\section{Las Crónicas de Indias en la ópera barroca Discursos y géneros}

ANa NúNEZZ RONCHI

Université de Lorraine - Metz

La ópera no es cosa de historiadores Carpentier, Concierto barroco ([1974] 1983: 192)

a historiografía indiana ingresa en la ópera prácticamente desde los inicios o Colonización de América y de diverso ámbito lingüístico así lo atestiguan: la semiópera de Henry y Daniel Purcell The Indian Queen (Londres, 1695; libreto adaptado de un drama heroico de John Dryden y Robert Howard), el "drama $[s i c]$ per musica" Motezuma de Antonio Vivaldi (Venecia, 1733; libreto de Alvise Giusti), la ópera-ballet Les Indes Galantes de Jean-Philippe Rameau (París, 1735; libreto de Louis Fuzelier) y la ópera seria Montezuma de Carl Heinrich Graun (Berlín, 1755; libreto de Federico II el Grande - de quien este año se celebra el 300 aniversario -, escrito originalmente en francés y traducido al italiano por Giampietro Tagliazucchi).

Sin embargo, la interpretación de este fecundo encuentro, ulteriormente reiterado en innumerables ocasiones (son hoy día alrededor de un centenar las óperas sobre la Conquista española de América)', no deja de plantear

1 Véanse, Martens, F.H., 1926, A Thousand and One Nights of Opera, Nueva York, Appleton and company; Pisano M.V., 2006, A Chronological Listing of Musical Works on American Indian Subjects composed since 1608, Nueva York,Vassar College, 2006; Máynez 2009: 560. 
serios problemas de orden (inter)textual, dada por un lado la disparidad de las normas (conjunto de prescripciones positivas y negativas, y de licencias) que rigen cada una de las semióticas y los discursos historiográfico y músicoliterario, la variabilidad de esas normas y las problemáticas nociones de intertextualidad y veridicción. Creemos que únicamente la teoría semánticointerpretativa de François Rastier, respetuosa de la variedad y especificidad de los discursos y los géneros textuales, y alejada de cualquier pretensión realista, podría venir a subsanar esas dificultades.

Muy empleada pero raramente definida, la noción de intertextualidad ha gozado de amplia fortuna en los estudios literarios, sin que por ello se hayan podido delimitar sus usos, ni limitar sus abusos.

El término análogo a intersubjetividad lo propone Julia Kristeva en un ensayo de 1966, ${ }^{2}$ Le mot, le dialogue et le roman, consagrado al aún poco conocido Bajtín: «Todo texto se construye como un mosaico de citas, todo texto es absorbción y transformación de otro texto. En el lugar de la noción de intersubjetividad se instala la de intertextualidad, y el lenguaje poético se lee, al menos, como doble». (Guillén 1985: 310).

Unos años más tarde, en 1969, Kristeva proponía ampliar - ¡vasto programa! - el sentido de un signo textual a:

[...] todos los sentidos que el significante de ese conjunto fónico o gráfico puede recubrir (sus homónimos); todos los sentidos idénticos al (a los) significado(s) de ese conjunto (sus sinónimos); todos los homónimos y todos los sinónimos de ese conjunto no sólo en una lengua dada, sino en todas las lenguas a las que pertenece como un punto del infinito; todas las acepciones simbólicas en los diferentes corpus míticos, científicos, ideológicos. (1981: 125).

Aun cuando el término intertextualidad pueda considerarse un feliz hallazgo, en cambio su imprecisión nocional y metodológica, evolucionando junto con los postulados del postmodernismo, ha sido cada vez más desconcertante. Mientras algunos (Culler 1981: 111-16) recurrían a las controvertidas nociones de presuposición y de implicación, otros distinguían tres tipos de conexiones textuales: la intertextualidad general (relaciones intertextuales entre textos de autores distintos), la intertextualidad restringida (relaciones intertextuales entre textos de un mismo autor) y la autotextualidad (relaciones posibles de un texto consigo mismo). No obstante, este acercamiento acabó distanciándose incomprensiblemente

2 Publicado en 1967 (nota de la autora). 
de cualquier intertextualidad de tipo genérico o discursivo, que es la que reinvidicamos aquís.

Que la historia está sujeta a la verdad, y que esta es el «ánima» de aquella4, es algo que los historiadores de Indias no cesaban de reiterar en sus escritos. Todos, o casi, dicen poseer la verdad, o al menos perseguirla ${ }^{5}$, y estigmatizan a sus antecesores por sus supuestas falsedades, mentiras y fabulaciones. He aquí por ejemplo lo que afirmaba el soldado Bernal Díaz en su Historia verdadera (1632) quien, descontento con la versión de la conquista de México proporcionada por López de Gómara, aseguraba suministrar a sus lectores la verdadera versión de los hechos, como bien indica el título de su crónica:

Estando escribiendo en esta relacion, acaso vi una historia de buen estilo, la cual se nombra de un Francisco López de Gómara, que había ${ }^{6}$ de las conquistas de México y Nueva-España, y cuando leí su gran retórica, y como mi obra es tan grosera, dejé de escribir en ella [...]; y estando tan perplejo como digo, torné a leer y a mirar las razones y pláticas que el Gómara en sus libros escribió, e vi desde principio y medio hasta el cabo no llevaba buena relación, y va muy contrario de lo que fue e pasó en la Nueva España, y cuando entró a decir de las grandes ciudades, y tantos números que dice que había de vecinos en ellas, que tanto se le dio poner ocho que ocho mil (Bernal Díaz 2009: 104; Cap. xviii)

Y cuando en 1684, el Cronista Mayor de Indias Solís y Rivadeneyra, revisita la historia de México, no duda en denigrar la crónica de Bernal por lo que considera su evidente parcialidad (1684: 129; Lib. II, Cap. xiii):

Saliò despues una Historia particular, de Nueva España, obra posthuma de Bernal Díaz del Castillo. [...] Passa oy por historia verdadera. [...] Obra que no tuvo la vista libre de passiones, para que se fuesse bien governada la pluma: muestrasse tan satisfecho de su ingenuidad, como quexoso de su

3 Sobre esta cuestión, véase Pincemin y Rastier "Des genres à l'intertexte" 1999: 102.

4 «Lo que toca á la verdad, que es donde consiste el ánima de la historia» (Agústín de Zárate

"A la majestad del rey de Inglaterra, Principe Nuestro Senor, Don Felipe II" Historia del Descubrimiento 1577); "conformándome con aquella verdadera sentencia del sabio que dice: que la boca que miente, mata el ánima» (Fernández de Oviedo 1535Lib. I.). Véase el topos expresado por Cabrera de Córdoba según el cual la historia había recibido de Saturno la capacidad de «dezir verdad» (Cabrera de Córdoba [1611] 1948: 16; Lib. 1, disc. 3).

5 Bernal Díaz (Historia verdadera Dastin 2009: 1: 107; Cap. xviii); «hablo con verdad por lo que sé y he visto todo el dicho tiempo» (Las Casas Brevísima relación de la destrucción de las Indias, Cambio 16, 1992: 13).

6 Errata por «habla», según la lectura del texto definitivo publicado por el CSIC, y que sigue la edición citada. 
fortuna: andan entre sus renglones muy descubiertas la embidia, y la ambiciõ (1684: 5b; Lib. I, Cap. ii).

si bien para algunos episodios, Solís no tiene empacho en seguir «a Bernal Diaz Castillo, que dice lo que viò, y [cuenta] lo mas semejante a la verdad» (1684: 29b; Lib. I, Cap. x).

Desde el punto de vista de la veridicción, notemos sin embargo que, sobre algunos de los episodios más emblemáticos del Descubrimiento y la Conquista de México (los primeros contactos en tierras yucatecas, el encuentro de Cortés con Moctezuma, la prisión y la muerte del emperador mexica, la llamada Noche Triste, el cerco a Tenochtitlán, la toma de la capital azteca, la captura o la entrega de Cuauhtémoc), cronistas, historiadores o relatores como Cortés, Gómara, Fernández de Oviedo, Cervantes de Salazar, Bernal Díaz, Alva Ixtilxóchitl, Tezozómoc, Muñoz Camargo, Solís de Rivadeneyra o el apasionado Las Casas se contradicen casi continua e irremediablemente, pues no solo presentan una perspectiva particular, sino que se inscriben a menudo dentro de prácticas sociales y discursivas divergentes ${ }^{7}$.

Así, la afirmación según la cual «[...] un escrutinio imparcial y exhaustivo de toda la información contenida en las Cartas [de relación de Hernán Cortés] revela que éstas tienen siempre un referente real, que son sucesos históricos, y por ende públicos. La existencia de éstos es por tanto corroborable no sólo por el testimonio de otros cronistas sino por la abundante documentación conservada, gran parte de la cual tiene carácter legal» (Delgado Gómez 1993: 55 $)^{8}$ resulta inadmisible para la semántica interpretativa, ajena a cualquier pretensión realista, y más generalmente, para una semiótica de las culturas: «Promus au rang d'observables, les faits humains et sociaux restent le produit de constructions interprétatives» (2002: 4). Jorge Checa ha podido notar asimismo que, «De entrada, la tentación de atribuirle a la experiencia una completa inmediatez se hace problemática cuando notamos cómo incluso hechos nominalmente empíricos nunca existen con independencia de su descripción»(Checa 1997: 13).

7 Desde la perspectiva de la semántica interpretativa, cada discurso cuenta con un número determinado de géneros y cada género tiene su vocabulario de construcción, sus formas de organización, sus contenidos esperables, sus modos redaccionales (Pincemin y Rastier 1999: 87-92).

8 Delgado Gómez (Delgado Gómez “Introducción”, Cortés, Cartas de relación 1993: 56) afirma seguidamente que "[...] Cortés selecciona, maneja e interpreta la realidad de acuerdo a sus intereses. Pero no por ello 'inventa' o recrea una realidad al modo que lo hace una novela, cuya realidad autosuficiente no necesita el sustento de un referente exterior al autor» (Delgado Gómez "Introducción", Cortés, Cartas de relación 1993: 56). 
El incauto lector, contrariado por tanta verdad autoproclamada pero difícilmente hallada, y aturdido por la circularidad y la autoreferencialidad de los testimonios cronísticos, vuelve entonces la mirada hacia los mal llamados textos "ficcionales»" - entre los que figuran sin duda los libretos de las óperas mencionadas arriba -, con la esperanza de encontrar en ellos un tirano menos despótico que aquel proclamado por los historiadores indianos.

Pero he aquí de nuevo a los actuales paladines del realismo empírico, que pretenden que las obras literarias se conformen no sólo al criterio aristotélico de verosimilitud vigente en el Barroco ${ }^{10}$, sino también al de veridicción (definida como la capacidad del lenguaje para expresar la verdad):

La semántica de la referencia es fundamental para nuestra tradición metafísica, ya que describe las condiciones bajo las cuales el lenguaje puede decir la verdad. Nuestra filosofía está obsesionada con ella desde el Cratilo hasta Word and Object (Quine) y Les mots et les choses (Foucault). (Rastier 1991: 82).

Así, sobre la ópera del cardenal Ottoboni, presentada en Roma en 1690 y considerada hoy día como la primera ópera americana de la historia de la música, se dijo en 1992 que su libreto era «improbable» (Heck 1992: 242), sin duda porque Ginacra, el emperador de una región llamada Motenzuma [sic], se prendaba de Anarda, la esposa de Colón, venida con él a tierras americanas. De The Indian Queen, de Henry y Daniel Purcell (1695), los más eminentes críticos han asegurado que su intriga era «absurda» $\mathrm{y}$ «traída por los pelos» ${ }^{11}$, y han fustigado a John Dryden, autor del drama anterior homónimo y futuro historiógrafo real (1670) por sus imperdonables lagunas

9 El historiador no debe tratar «de cosas falsas, verosímiles ni imaginadas», aseguraba en 1578 la preceptiva de Rodrigo Espinosa de Sanctayana (Arte de Retórica, 1578, cit. in "Estudio preliminar", Historia para entenderla y escribirla, Cabrera de Córdoba, ed. Santiago Montero Díaz, p. XI-LVI, 1948: xxxiii).

10 Así lo afirma Alvise Giusti en la presentación de su libreto: «Tutto ciò, che di vero abbandono, e che di verisimile aggiongo è per adattarmi alla Scena» (Giusti 1733: s.p.). Lo verosímil no estaba reñido con lo maravilloso. Cascales, en sus Tablas poéticas ([1617] ed. A. de Sancha, Madrid, 1979: 169-71), afirmaba por ejemplo que «si no es maravilloso poca delectación puede engendrar [...]. Causan admiración las cosas que suceden sin pensar, o porque creemos venir de las manos de Dios o por su propio movimiento [...]. Así que gallardean la fábula en grande manera cosas que fuera de la imaginación y esperanza acaecen maravillosamente». Sobre la presencia de lo maravilloso en la ópera, véase Algarotti F., 1783, Saggio sopra l'opera in musica, Livorno, Per Marco Coltellini in Via Grande. http://www.librettidopera.it/zps_dor/cr_es/saggi_algarotti_002.pdf

11 «Aberración melodramática» dice de ella el violinista Samuel Máynez Champion (2009: 559) 
en materia de historia y geografía porque, entre otras cosas, hacía colindar México con el Perú y unía en feliz matrimonio a Montezuma con una princesa incaica ${ }^{12}$. Respecto de la ópera-ballet Les Indes Galantes de Rameau (1735), se nos informa de que ya en noviembre de 1735, Le Mercure de France «ne trouva à son goût que les Incas [la segunda entrada], critiquant le livret entre autres, pour ses libertés... géographiques» (Kaminsky 2011: 197-98), dado que al parecer no respetaba la regla de las tres unidades:

Chaque partie séparée des Ballets anciens étoit nommée Entrée. Dans les Modernes, on a conservé ce nom à chacune des actions séparées de ces Poëmes. Ainsi l'on dit: l'Entrée de Tibulle dans les Fêtes Grecques \& Romaines, \& l'Entrée [p. 439] des Incas dans les Indes Galantes. Il seroit ridicule que l'on fît commencer l'action dans un lieu, \& qu'on la dénouât dans un autre. Le tems d'une Entrée de Ballet doit être celui de l'action même : on ne suppose point des intervalles: il faut que l'action qu'on veut représenter se passe aux yeux du Spectateur, comme si elle étoit véritable. Quant à sa durée, on juge bien que puisque le Ballet exige ces deux unités, il exige à plus forte raison, l'unité d'action : c'est la seule qu'on regarde comme indispensable dans le grand Opéra; on le dispense des deux autres : l'entrée de Ballet, au contraire, est astreinte à toutes les trois (Paris: Lacombe, 1776: 438-439).

Estos juicios han sido reiterados en 1994 por el eminente americanista Pierre Duviols, quien se refería a estas óperas como a "Estas indianerías', que tan a menudo se desvían de la verdad histórica» (Duviols 1994: 13) ${ }^{13}$. Y si el libreto de la ópera Montezuma de Carl Heinrich Graun (1755) se ha ganado los favores de la crítica por su supuesta adecuación a la realidad

12 Las suposiciones sobre los conocimientos geográficos de Dryden no son ni de nuestra competencia ni de nuestro interés. Sin embargo, todo parece indicar que La reina india refleja con mayor o menor exactitud el estado de las divisiones administrativas de los territorios americanos de mediados del siglo Xvir. En efecto, «Peruana containeth the Southern Part of America, and is tyed to Mexicana, by the Istmus or Strait of Darien» (Heylyn 788); "The second part of all America is called newe Spaine. It extendeth from the Tropicke of Cancer in twentie degrees and a halfe, unto the ninth degree [...]. The third part of America is called Peru, it is very great, and extendeth it selfe in Latitude from the tenth degree unto the three and fiftieth beyond the Equator, to wit, as I have said before, unto the streight of Magelan» (Hakluyt vol. 8 1927-1928: 450); de suerte que, incluso en la tardía fecha de 1695, año probable del estreno londinense de la ópera de Purcell, la contigüidad de los imperios mexicano y peruano no tenía por qué desconcertar a su entusiasmado público.

13 Recuérdense las «Indian Rarityes» expresadas ya en 1667 por Caryll (1667: A2; Pról., vv. 1-6) en referencia a las piezas teatrales The Indian Queen y The Indian Emperour de John Dryden. 
histórica ${ }^{14}$, sin embargo se ha granjeado las iras de un público español furioso con el tratamiento despectivo que el libreto de Federico II el Grande y la puesta en escena de Claudio Valdés Kuri en 2010 hacen de Cortés, gran héroe nacional y literario, y de los españoles en general, pueblo elegido por Dios $^{15}$.

Pero de todo ello, lo que más impacienta a los críticos actuales suele ser el final feliz (lieto fine) de estas óperas ${ }^{16}$ que, lejos de circunscribirse a los mitos clásicos, tienen la pretensión de reescribir la Historia. En efecto:

A crucial point in any opera seria dealing with the history of the Conquista had to be the end, because the librettist necessarily found himself caught between two conflicting constraints: On the one hand, in accordance with the aesthetics canon of opera seria the action had to move to a happy conclusion, with the re-establishment of sovereignty and an atto di clemenza on the part of the ruler; conversely, any happy finale would be in flagrant contradiction of the known facts of history (Maehder 2008: 72)

Así, Montezuma, a diferencia del monarca sañudo y tiránico que describen las crónicas (Gómara 2007: 135, Cap. LXVII; Solís 1684: 84-85; Lib. II, cap. 3; 128; Lib. II, Cap. 13) ${ }^{17}$, aparece ya como el restaurador del

14 «Federico II no dudará en pasar a cuchillo a todos los mexicanos tras asistir como espectador privilegiado de la muerte de Moctezuma y Eupaforice, en una afirmación de la historia por encima de cualquier otra exigencia dramática» (Jouve-Martin J. Bulletin of Hispanic Studies, v. 87 n 2 (2010: ): 203-220 p. 209).

15 «el cual demonio tenía estas gentes, por la permisión de Dios, opresas y captivas tantos tiempos había, era justo que por el mundo se supiese en qué manera tanta multitud de gentes como destos indios había fue reducida al gremio de la santa madre Iglesia con trabajo de españoles; que fue tanto, que otra nación alguna de todo el universo no los pudiera sufrir. Y así, los eligió Dios para una cosa tan grande más que a otra nación alguna» (Cieza de Léon, "Proemio al lector", La crónica del Perú, Ed. Manuel Ballesteros Madrid: Historia 16, 1984: 62).

16 «Die Kombination von Liebesintrige und mythologischem oder antikisierend historischem Sujet, verbreitete Strukturkonvention in der europäischen Oper des 17. und 18. Jahrhunderts, diente nicht primär der Darstellung historischer Realitäten, sondern der Erzeugung emblematischer Situationen des Konfliktes von Pflicht und Neigung unter Standespersonen. Aufgabe der Musik mußte es sein, diese auf in Arienform kondensierbare Emotionen abzutasten. Kategorien einer vage realistischen Bühnendarstellung des 19. Jahrhunderts, die den Erwartungshorizont gegenüber musiktheatralischer Darstellung nachhaltig geprägt haben, sind mithin dem Verständnis der Dramaturgie barocker Opernlibrettistik selten förderlich» (Maehder, "Mentalitätskonflikt" 1992: 136).

17 El propio Tezcalipoca, «dios infausto, y formidable» decía así en la crónica de Solís: «Ya, Mejicanos infelices, perdieron la fuerza vuestros Conjuros; ya se desató enteramente la trabazon de nuestros pactos. Decid à Motezuma, que por sus crueldades y tyranìas tiene decretada el Cielo su ruina; y para que le representéis más vivamente la desolacion de su Imperio, bolved a mirar essa Ciudad miserable, desamparada ya de vuestros Dioses» (Solís 1684 p. 211-212 ; Lib. III, Cap. viii). 
orden político y religioso en la ópera de Purcell, ya como un epítome del rey ilustrado en Graun ${ }^{18}$; Ramiro, hermano de Hernando en la ópera de Vivaldi, une su destino al de la hija del emperador Motezuma, que no sólo no muere, sino que además bendice la unión de los amantes; y Rameau hace perecer en los abismos de un volcán en erupción a Huáscar, duodécimo emperador inca según la historiografía oficial, pero transformado aquí en sumo sacerdote enamorado de la palla Phani.

Con todo, la convención del final feliz, de casi obligado cumplimiento, constreñía, al menos hasta finales del siglo xvinI, a reescribir el desenlace de mitos de la Antigüedad clásica como el de Orfeo (Peri, Monteverdi, Gluck) o acontecimientos de la historia antigua como el de Nerón y Popea (Monteverdi) ${ }^{19}$, de tal manera que el final de la ópera de Graun, en que Montezuma es ejecutado junto a sus generales ${ }^{20}$, debería ser considerado no como una encomiable adecuación a la verdad histórica ${ }^{21}$, sino como una transgresión de la norma operística, lo que permite, incidentalmente, darle sentido a la aparente contradicción entre este trágico final y la música alegre y festiva en re mayor compuesta por Graun para este episodio (Maehder 1992: 157).

Por otra parte, el recurso al final feliz, al igual que ocurre con la presencia de la sanción final en la comedia áurea o en el drama heroico inglés, constituye un interpretante de peso para la construcción retrospectiva de las evaluaciones de las piezas lírico-dramáticas que, a diferencia de las crónicas

18 Aunque de acuerdo con ciertas normas de etiqueta, está mal que lo diga el propio Moctezuma: «MOCTEZUMA: Sí, mio Tezeuco, Messico è felice. Frutto di quella libertà, che, unita alla prudenza, al solo fren soggiace delle leggi, ch'io stesso sono il primo ad osservare; il popol mio di stabil gaudio e bel riposo abbonda, e il mio poter su l'amor suo si fonda» (Graun, Montezuma, Leipzig: Breitkopf \& Härt 1904: 11; I, i).

19 Si bien la Dido y Eneas de Purcell (repr. 1688) constituye una doble excepción tanto por ser enteramente cantada como por su final, muchas óperas italianas de temática similar casaban a Dido con Irabus al final de la intriga, logrando así un final feliz (Ellen T. Harris, Dido and Aeneas (Oxford: Clarendon Press, 1987: 30).

20 Esta ejecución tiene lugar fuera de escena (GraunMontezuma, Leipzig: Breitkopf \& Härt 1904: 213; III, v; Graun, Montezuma. Leipzig: Verlag von Breitkipf, Härtel in, 1904), posiblemente por razones de decoro, y a manos de los españoles, contrariamente a lo que aseguran en general los cronistas españoles.

21 «Federico II no hace historia, tampoco hace antropología a la manera de Montaigne, sino que - como los enciclopedistsas y el barón de Lahontan - hace de esa sociedad [mexicana] un paradigma eminentemente utópico de orden ético, político y religioso frente al cual destaca los defectos de las instituciones de la sociedad europea» (Ballón Aguirre "Montezuma de Federico II el Grande, Rey de Prusia (ideología y utopía", in De palabra, imágenes y símbolos, homenaje a José Pascual Buxó. Ed. Enrique Ballón Aguirre y Oscar Rivera Rodas. México: UNAM, 2002: . 313-365. 354). 
de Indias, no suelen contar con un enunciador único capaz de encuadrar los diferentes enunciados y atribuirles un valor de verdad, aunque este valor de verdad sea a veces indecidible ${ }^{22}$ :

Si en el relato clásico los enunciados son asumidos por un narrador único que permite el encuadramiento relativamente homogéneo de los enunciados, no sucede lo mismo en los textos de tipo dramático, donde la multiplicidad de los enunciadores apunta hacia la multiplicidad de modalidades veridictorias o evaluativas. Así, en el teatro, sólo las indicaciones escénicas, y a veces las palabras de un recitante, aseguran la función de narración sin que esté presente el narrador como actor del relato; fuera de esto, queda asegurada por los actores del relato mismo [...] Un enunciado será verdadero si puede ser confirmado por un actante oponente (Rastier 1973: 93-94).

Además del componente dialógico (que da cuenta de estos fenómenos de veridicción dentro del universo ficcional, así como de las modalidades evaluativas), la diversidad de normas entre discursos y géneros atañe a los demás componentes de la textualidad (la temática, la dialéctica y la táctica), y a sus interacciones normadas ${ }^{23}$.

En cuanto al componente temático, es importante señalar que, al emigrar de un texto a otro, los vocablos cambian de sentido, dado que reciben determinaciones del nuevo contexto en el que se encuentran, lo que no deja de incidir, recíprocamente, en el componente dialógico. Es el caso de denominaciones tales como Mo(n)tezuma, Zempoalla, Traxalla, Teutile, etc., cuyo contenido semántico y cuyos roles actanciales varían de un texto a otro y, a fortiori, de un discurso a otro.

Veamos por ejemplo el caso de The Indian Queen. A los asiduos lectores de las crónicas españolas puede llamarles especialmente la atención la peculiar resemantización de algunos de los gentilicios y nombres propios

22 A raíz de un episodio acaecido a Viracocha Inca, Cieza se interroga sobre la existencia de puentes de viga en la región de Cayto Marca [Cutomarca], concluyendo que «Unos dicen que sí y otros afirman que no» (Cieza de León 2005: 386). En la ópera, existe algún caso particular en que un personaje narrador se inserta en la acción dramática, como es el caso de la ópera Montezuma de Roger Sessions (Berlín, 1964). Sin embargo, al dramatizarse, el narrador pierde su estatus como garante de la verdad ficcional.

23 La temática da cuenta del universo semántico representado; la dialéctica se refiere a los intervalos temporales del tiempo representado, de los estados y de los procesos que se desarrollan en él; la dialógica trata de las modalidades enunciativas y evaluativas y la táctica de la disposición lineal de las unidades semánticas). Más precisamente, un género se define como «un mode d'interaction normé entre composantes» (Rastier "Éléments de théorie des genres», 2001). 
de esta ópera. Frente a las crónicas que no cesaban de afirmar el carácter determinante (pero siempre subordinado) de la ayuda brindada por los leales «amigos» cempoaltecas y tlascaltecas en el proceso de conquista, The Indian Queen invierte las evaluaciones atribuidas a Zempoalla y Traxalla respecto de sus homónimos cronísticos, al tiempo que los individualiza ${ }^{24}$. $\mathrm{Si}$ bien es cierto que muchos autores coloniales encomiaban la labor de los tlaxcaltecas y otros aliados:

Hermanos y compañeros míos, ya veis acabados y puestos a punto aquellos bergantines, y bien sabéis cuánto trabajo nos cuesta, y cuánta costa y sudor a nuestros amigos hasta haberlos puesto allí; muy gran parte de la esperanza que tengo de tomar en breve a México está en ellos. (Gómara 2007: 249; Cap. cxxx).

Hay que señalar que suelen hacerlo recalcando su papel secundario, como lo muestra el orden de exposición que hace Cortés en su «Segunda relación», en el que sitúa a los españoles por delante de los équidos, y estos a su vez por delante de los tlaxcaltecas: «En este desbarato [se refiere a la "Noche Triste", como la llamó Gómara] se halló por copia que murieron ciento cincuenta españoles y cuarenta y seis yeguas y caballos y más de dos mill indios que servían a los españoles» (Cortés 1993: 282). Y prosigue en el mismo registro: «no teníamos después de Dios otra seguridad sino la de los caballos» (1993: 285).

Desde el punto de vista del componente dialéctico, notemos por ejemplo que el suicidio, prácticamente ausente de la comedia áurea española dadas las prescripciones tridentinas en materia de actos de «soberbia y desesperación ${ }^{25}$, aparece profusamente representado en la ópera seria y en el teatro heroico inglés, donde el suicidio podía representarse sobre los

24 Es interesante notar que, en su Brevísima relación, Las Casas se distancia de los españoles ya mediante un genérico «ellos» (Cambio 16, 1992: 36), ya mediante el uso de apelativos perifrásticos: «un infelice gobernador» (Cambio 16, 1992: 27), «el capitán de los españoles» (Cambio 16, 1992: 40), «aqueste capitán tirano» (Cambio 16, 1992: 44). Por el contrario, los caciques son designados mediante su antropónimo: Guarionex, Guacanagarí, Caonabó, Anacaona y Higuanamá en la Española (Cambio 16, 1992: 16-21), Hatuey en Cuba (Cambio 16, 1992: 24), "nuestro universal señor Motenzuma» en la Ciudad de México (Cambio 16, 1992: 40). Otro representante de la llamada Leyenda Negra, el italiano Girolamo Benzoni, cuya Historia del Nuevo Mundo se publicó en 1565, ofrece por su parte la particularidad, muy moderna, de incluirse a sí mismo dentro de la clase semántica que denigra.

25 Jaime Fernández S. J., «Reflexiones sobre el suicidio en el teatro de Lope de Vega». http:// cvc.cervantes.es/literatura/aiso/pdf/03/aiso_3_2_017.pdf. 
escenarios mismos ${ }^{26}$. Inversamente, cuando las crónicas de Indias y los textos coloniales mencionan el suicidio (y el infanticidio) de la población indígena, se constata una diferenciación tanto en términos de actores involucrados como de motivaciones y formas, ya que este no atañe a personas aisladas, ni se relaciona con cuestiones sentimentales como en la ópera, sino con la situación de deculturación a la que se vieron sometidos los pueblos indígenas por efecto de la Conquista, como lo señala esta carta del Provincial de San Francisco, fechada el 18 de marzo de 1600:

En sacándolos de las tierras donde nascen y se an criado se consumen y acaban de manera que pueblos que solían tener quince o veinte mill tributarios el día de oy no tienen tres ni quatro mill; [...] se van a los montes y como salvaxes se matan. [...] es gente tan melancólica que quitarles desto los hacen morir con facilidad, y algunos se han ahorcado, primero sus hijos y mugeres. (Bernand et Gruzinski 1993: 684n)

Por último, es necesario señalar, sin entrar en más detalles, que cada tradición ha establecido en qué lengua(s) conviene historiar, cantar, recitar, declamar, evangelizar, filosofar, etc., pues la especialización lingüística está vinculada a la especialización de las prácticas socializadas, como lo atestiguan las diferentes políticas lingüísticas de la Corona española tanto en sus territorios peninsulares como ultramarinos, o la famosa «Querelle des Bouffons» en la ópera francesa.

Estos planteamientos nos llevan entonces a hacer varias consideraciones de orden teórico dentro del marco general de la semántica interpretativa.

Por un lado, no hay duda de que muchos de los juicios presentados arriba están relacionados con la jerarquización de las prácticas socializadas, ya según un criterio de veridicción (del que depende la problemática de la verosimilitud), ya en función de un criterio que podríamos llamar «de nobleza» (artes serviles o artes nobles). En efecto, la poesía, beneficiaria de la prestigiosa teoría de la inspiración (en Hesiodo, por ejemplo) era considerada un arte noble (Rastier 1992), mientras que la pintura no gozaba del estatuto de «arte» y era calificada de oficio menor, hasta el punto de no figurar siquiera necesariamente en el catálogo de las artes mecánicas o serviles. A partir del Renacimiento, la pintura adquirió el estatuto de ciencia con la

26 Véase el diálogo mantenido entre el indiano y el propio Vivaldi en Concierto barroco de Carpentier: "- "Pero... Montezuma fue lapidado." / - "Muy feo para un final de ópera. Bueno, si acaso, para los ingleses que terminan sus juegos escénicos con asesinatos, degollinas, marchas fúnebres y sepultureros. Aquí la gente viene al teatro a divertirse"» ([1974] 1983: 193). 
inclusión de la perspectiva lineal (Leonardo da Vinci), y ambas, pintura y poesía, figurarían entre las artes musicales (Marsilio Ficino), entre las nobles (Giovanni Pietro Capriano) o entre las memoriales (Ludovico Castelvetro). En el siglo XviII, Charles Batteux rehabilita la pintura al incluirla entre las «bellas artes», término que acuña y en el que incluye la danza, la escultura, la música, la pintura y la poesía, añadiendo posteriormente la arquitectura y la elocuencia. Si el criterio de nobleza permitía situar la música entre las artes ilustres (por su pertenencia al quadrivium, si bien luego reivindicada por el trivium), por el contrario este arte se encontraba en el puesto menos prestigioso de la escala imitativa, precedida por la poesía (libreto) y la pintura, que ostentaba el primer lugar. En efecto, «cual sea que fuera el rango de la pintura, siempre era considerada como ejemplar» dado que «el conocimiento visual era considerado verídico ya que directo, y el conocimiento de oído era juzgado como indirecto y discutible» (Rastier 1992). Algo similar afirma Solís en su Historia de la Conquista de México:

[...] siendo Maxima evidente, que abultan mas en el animo las noticias que se reciben por los ojos; assi como pueden menos con el corazon las que se mandan por los oìdos (1684: 512; Lib. V, Cap. xix).

Y como la poesía (de los libretos) imitaba las acciones y era considerada «lenguaje del espíritu», gozaba en general de mayor prestigio que la música (la «retórica de los Dioses», según Denis Gaultier, 1652), que imitaba los sentimientos y era considerada «lenguaje del corazón». De ahí que, y especialmente a partir del descubrimiento de la Institutio oratoria de Quintiliano en 1416, tuviera lugar una asombrosa proliferación de tratados músico-retóricos (desde Listenius a Mattheson, pasando por Dressler, Burmeister y Kircher). Para subsanar esta deficiencia imitativa, algunos optaron por calificar la música como «pintura de la poesía»:

«Maintenant quelle est la beauté de la Musique des Opera? C'est d'achever de rendre la Poësie de ces Opera, une peinture vraiment parlante» (Lecerf de la Viéville 1704: 169);

o bien simplemente la antepusieron autocráticamente a la poesía:

[Jacques-Joseph-Marie] Decroix, quant à lui, rapporte la réponse que Rameau aurait faite à sa chanteuse des Paladins, Sophie Arnoult, qu'il faisait répéter et qui demandait un tempo plus lent pour une meilleure compréhension du texte: «Peu importe qu'on entende vos paroles si on entend ma musique» (Rousset 2007: 153). 
Si estos criterios permanecían vigentes en los siglos XVII y XVIII ${ }^{27}$, hoy día deben ser superados en pro de un principio de igualdad de todas las artes, lo que no contradice el principio de diversidad. Y es que contrariamente a lo que suele ser la tendencia de la crítica actual, que se inclina por la confusión ${ }^{28}$ o la inexistencia de los géneros textuales, y reivindica una intertextualidad indiscriminada, creemos al contrario que cada práctica social cuenta con una serie de discursos y géneros cuyas normas le son propias y que no son directamente transponibles de un género a otro ni, a fortiori, de un discurso a otro:

Si los discursos pueden influenciarse los unos a los otros y compartir rasgos comunes dentro de lo que Foucault llamaba episteme, cada uno de los sistemas genéricos es sin embargo autónomo y evoluciona según sus propias leyes, como lo demuestran sus evoluciones diacrónicas diferentes. (Rastier 2000: 255)

Esto lo diría más groseramente el personaje de Vivaldi en Concierto Barroco de Alejo Carpentier, novela que reconstituye el estreno de la ópera del compositor veneciano en 1733. En efecto, hastiado de las recriminaciones que le hace el indiano sobre la ahistoricidad y los anacronismos en su ópera, responde encolerizado: "No me joda con la Historia en materia de teatro» (1983: 193) ${ }^{29}$. O dicho de forma más decorosa, como corresponde al género en el que estamos escribiendo: cada discurso y cada género cuentan con un régimen de producción y de interpretación propio.

Por otro lado, todo vocablo trasladado de un texto a otro texto (como por ejemplo el de las denominaciones de los personajes) sufre

27 El Siglo de las Luces se mostró en efecto incapaz de cuestionar tanto el principio de mímesis como el de nobleza: «La peinture montre l'objet même; la poésie décrit; la musique en excite à peine une idée» (Diderot 1987: 84cit. Stefanovic La musique comme métaphore 2006: 223).

28 Por ello disentimos de las propuestas de Hayden White, Metahistory. The Historical Imagination in Nineteenth-Century Europe (Baltimore, The John Hopkins University Press, 1973); William Nelson, Fact of Fiction. The Dilema of the Renaissance Storyteller (Cambridge, Mass. Harvard University Press, 1973). Walter Mignolo, «El metatexto historiográfico y la historiografía indiana», MLN, 96 (1981), Enrique Pupo Walker, La vocación literaria del pensamiento histórico en América. Desarollo de la prosa de ficción: siglos XVI, XVII, XVIII y XIX (Madrid, Gredos, 1982), Roberto E. Lewis, «Los Naufragios de Alver Núñez: historia y ficción», Revista iberoamericana, 48.120-121 (1982): 681-94.

29 El supuesto «irrisolto conflitto tra storicità e fantasia, tra l'arte dello storiografo spagnolo e le esigenze dello spectacolo teatrale in musica a Venecia nel primo Settento» (Antuono, «Tra storicità e fantasia» 284) puede resolverse mediante la noción de régimen interpretativo. 
una resemantización que depende en gran medida del nuevo contexto, y particularmente del género y discurso textual en el que se inserta.

Por último, como lo permite percibir la autoreferencialidad ${ }^{30}$ de los enunciados pretendidamente veridictorios en las crónicas, es importante insistir en que, en la perspectiva de una semiótica de las culturas, que es la que adoptamos aquí, «les objets sont constitués par des évaluations sociales, et non par des données physiques» (Rastier 1997) y que «Loin de refléter la réalité, les signes la créent, et prenant cet effet (ou ce corrélat) pour une cause nous nommons réalité cet effet de réel» (Rastier 1992: 120).

Lo que transmiten las formas semióticas y los textos, aun cuando son históricos, no son verdades, ni datos, ni informaciones, sino normas, valores y contenidos socialmente evaluados. Por ello los conservamos, los releemos y los reinterpretamos ${ }^{31}$. Casi compulsivamente.

\section{Bibliografía}

Antuono, N. d', 2006, «Tra storicità e fantasia. La Historia della conquista de Mexico (1684) di Antonio de Solís e il Motezuma del poeta Alvise Giusti (1733) con alucuni referimenti al Concierto barroco di Alejo Carpentier (1974)», en: Le arti della scena e l'esotismo in età moderna, Francesco Cotticelli et Pologiovanni Maione (eds.), Nápoles: Turchini Edizioni, p. 271-284.

Ballón Aguirre, E., 2002, «Montezuma de Federico II el Grande, Rey de Prusia (ideología y utopía)», en: De palabra, imágenes y símbolos, homenaje a José Pascual Buxó, Enrique Ballón Aguirre y Oscar Rivera Rodas (eds.), México, UNAM.

Bernand, C. y S. Gruzinski, 1993, Histoire du Nouveau Monde, vol. 2, París, Fayard. Cabrera de Córdoba, Luis, [1611] 1948, De historia, para entenderla y escribirla, Santiago Montero Díaz (ed.), Madrid, Instituto de Estudios Políticos.

30 Tampoco conviene hablar de «falsificación» como proponen algunos autores, puesto que ello nos mantiene dentro de la lógica veridictoria: «Bernal, después de leer las crónicas de Gómara, Illescas, Giovio, se esfuerza por dar la versión verdadera de la conquista puesto que estos cronistas habían falsificado la historia con su retórica historiográfica humanística» (Green Jr, «La retórica y la crónica de Indias: el caso de Bernal Díaz del Castillo», AIH, Actas, VIII (1983: 647); "Conviene constatar aquí que la versión de Bernal es de igual modo una falsificación» (James Ray Green Jr, «La retórica y la crónica de Indias: el caso de Bernal Díaz del Castillo», AIH, Actas, VIII (1983: 648).

31 «[...] les données sont bien ce qu'on se donne»; «[...] elles sont ainsi les résultats initiaux d'un processus d'élaboration - et leur traitement produit des résultats ultérieurs, dans un cycle susceptible de récursivité» (Rastier 2010, «Objets et performances sémiotiques L'objectivation critique dans les sciences de la culture», Actes du colloque L'homme sémiotique, Namur, 19-21 avril $2010: 8-31$, p. 8). 
Carpentier, A., [1974] 1983, Concierto barroco, María Luisa Puga (ed.), México, D. F., Siglo XXI.

Caryll, J., 1667, The English Princess; Or, The Death of Richard the III. Londres, Printed for Thomas Dring, and are to be sold at his shop.

Cascales, F., [1617] 1979, Tablas poéticas, A. de Sancha (ed.), Madrid, Espasa-Calpe. Checa, J., 1997, Experiencia y representación en el Siglo de Oro, Valladolid, Junta de Castilla y León, Consejería de Educación y Cultura.

Cieza de León, P., [1553] 2005, El Señorío de los Incas, ed. Franklin Pease, Fundación Biblioteca Ayacucho.

Cieza de Léon, P., [1880] 1984, «Proemio al lector», La crónica del Perú, Manuel Ballesteros (ed.), Madrid, Historia 16.

Cortés, H., [1519-1526] 1993, Cartas de relación, Ángel Delgado Gómez (ed.), Madrid, Castalia.

Culler, J., 1981, The Pursuit of Signs: Semiotics, Literature, Deconstruction, Ithaca, Cornell University Press.

Delgado Gómez, A., 1993, «Introducción», Cartas de relación de Hernán Cortés, Ángel Delgado Gómez, Madrid, Clásicos Castalia, p. 9-72.

Díaz del Castillo, B., [1632] 2009, Historia verdadera de la Conquista de México, Madrid, Dastin.

Diderot, Denis, 1987, «Lettre à Mlle de la Chaux», en: Ecrits sur la musique, Béatrice Durand-Sendrail (ed.), París, Lattès.

Duviols, P., 1994, "La fascinación americana», en: Zavala, Huguette, América inventada, Fiestas y espectáculos en la Europa de los siglos XVI al XX. Antonio Urrutia y María José Riquelme (trads.), Madrid, Banco Santander de Negocios, 13.

Fernández de Oviedo, 1535, Historia general y natural de las Indias, Parte 1, http:// www.ems.kcl.ac.uk/content/etext/e026.html.

Garcilaso de la Vega, «Inca», [1609-1616] 1995, Los comentarios reales, México, D.F., Fondo de Cultura Económica.

Giusti, Alvise, 1733, Motezuma. Drama per musica da rappresentarsi nel Teatro di Sant'Angelo Nell'Autunno dell'anno 1733, Venecia, Appresso Marino Rossetti, in Merceria, all'Insegna della Pace.

González Maestro, J., 2003, «La risa en el Persiles», en: Lectures d'une oeuvre: «Los trabajos de Persiles y Sigismunda» de Cervantes, Jean-Pierre Sanchez (ed.), París, Editions du Temps, p. 157-201.

Graun, C.H., 1904, Montezuma, Leipzig: Breitkopf \& Härtel.

Green., J.R., Jr., 1983, «La retórica y la crónica de Indias: el caso de Bernal Díaz del Castillo», AIH, Actas, 8, http://cvc.cervantes.es/literatura/aih/pdf/08/ aih_08_1_069.pdf

Guillén, C., 1985, Entre lo uno y lo diverso: introducción a la literatura comparada, Barcelona, Editorial Crítica. 
Hakluyt, R., (ed. y trad.), [1598-1600] 1927-1928, The Voyages Traffiques of Discoveries of Foreign Voyagers with Other Matters Relating There-to Contained in the «Navigations, Vol. 9», J. MacLehose, Londres, J. M. Dent and Sons.

Harris, E. T., 1987, Dido and Aeneas, Oxford, Clarendon Press.

Heck, T., 1992, «The Operatic Christopher Columbus: Three Hundred Years of Musical Mythology», en: Images of America and Columbus in Italian literature, Dino S. Cervigni; Albert N. Mancini (eds.), Chapel Hill, NC, University of North Carolina at Chapel Hill, 236-278.

Heylyn, P. [1621] 1639, Microcosmus, Oxford, Printed by William Turner.

Jouve-Martin J., 2010, «Literatura, música e historia: La conquista de México en la ópera Montezuma (1755) de Federico II y Carl Heinrich Graun», Bulletin of Hispanic Studies, 87/2: 203-220.

Kaminski, Piotr, 2010, Lully, Rameau et l'opéra baroque français, París, Librairie générale française.

Kristeva, J., 1981, Semiotika 2, José Martín Arancibia (trad.), Caracas: Fundamentos.

Laporte, J. y S. R. N. Chamfort, 1776, Dictionnaire dramatique, Paris, Lacombe.

Las Casas, B. de, [1552] 1992, Brevísima relación, Madrid, Cambio 16.

Lecerf de la Viéville, J.- L., 1704, Comparaison de la musique italienne et de la musique française, Bruselas, chez F. Foppens.

López de Gómara, F., [1552] 2007, Historia de la conquista de México, ed. Jorge Gurría Lacroix, Caracas, Biblioteca Ayacucho.

López Pinciano, A., 1998, «Philosophía antigua poética», en: Obras completas, José Rico Verdú (ed.), Madrid, Fundación José Antonio de Castro.

Maehder, J., 1992, «Mentalitätskonflikt und Fürstenpflicht: Die Begegnung zwischen Conquistador und mittelamerikanischern Hersscher auf der barocken Opernbühne», en: Text und Musik. Neue Perspektiven der Theorie, Micheal Walter (ed.), Munich, Fink, p. 131-179.

Maehder, J.2008, «Alvise Giusti's Libretto Motezuma and the Conquest of Mexico in Eighteen-Century Italian Opera Seria», en: Vivaldi, «Motezuma» and the Opera Seria: Essays on a Newly Discovered Work and its Background, ed., Michael Talbot, Brepols, Turnhout, p. 63-80.

Máynez Champion, S., 2009, "Como turquesas que vagan en el tiempo...», Destiempos, 3/18, 553-577, http://www.destiempos.com/n18/maynez_champion. pdf.

Montero Díaz, S., 1948, «Estudio preliminar», en: Historia para entenderla y escribirla de Cabrera de Córdoba [1611], Santiago Montero Díaz (ed.), Madrid, Instituto de Estudios Políticos, xi-lvi.

Pincemin, B. y F. Rastier, 1999, «Des genres à l'intertexte», Cahiers de praxématique, 33, p. 83-111.

Rastier, F., 1973, Essais de sémiotique discursive, París, Mame.

Rastier, F., 1991, Sémantique et recherches cognitives, Paris, PUF. 
Rastier, F., 1992, «La généalogie d'Aphrodite. Réalisme et représentation artistique», Littérature, 87, p. 105-123.

Rastier, F., 1997, «Les fondations de la sémiotique et le problème du texte. Questions sur les prolégomènes à une théorie du langage de Louis Hjelmslev», Texto ! Textes et cultures http://www.revue-texto.net/1996-2007/Inedits/Rastier/Rastier_ Fondations.html.

Rastier, F., 2000, Arts et sciences du texte, París, PUF.

Rastier, F., 2001, «Éléments de théorie des genres», Texto ! Textes et cultures, http:// www.revue-texto.net/index.php?id=555.

Rastier, F., 2002, «L'action et le sens. Pour une sémiotique des cultures», Journal des Anthropologues, p. 85-86, http://jda.revues.org/2941.

Rastier, F., 2010, «Objets et performances sémiotiques - L'objectivation critique dans les sciences de la culture», Texto ! Textes et cultures, 15/4, http://www.revuetexto.net/index.php?id=2734.

Rousset, J.-P., 2007, Rameau, Arles, Actes Sud.

Solís y Rivadeneyra, A. de, 1684, Historia de la Conquista de México, Madrid, En la Impr. de Bernardo de Villa-Diego.

Zárate, A. de, 1577, "A la majestad del rey de Inglaterra, Principe Nuestro Senor, Don Felipe II», Historia del Descubrimiento y Conquista de la Provincia del Perú, http://bartolomedelascasas.es/paginas/zarate.htm.

Zavala, Huguette, 1994, América inventada. Fiestas y espectáculos en la Europa de los siglos XVI al XX, A. Urrutia y M. J. Riquelme (trads.), Madrid, Banco Santander de Negocios. 